\title{
Clinical Complications Associated with Spinal Cord Injury: A Narrative Review
}

\author{
Ibrahim Mohammed', Sahar ljaz², Morteza Gholaminejhad³, Gholamreza Hassanzadeh,4*
}

'Department of Histopathology, School of Medical Laboratory Sciences, Usmanu Danfodiyo University Sokoto, Nigeria.

2Department of Anatomy and Histology, University of Veterinary and Animal Sciences, Lahore, Pakistan.

${ }^{3}$ Department of Anatomy, School of Medicine, Tehran University of Medical Sciences, Tehran, Iran.

${ }^{4}$ Department of Neuroscience and Addiction studies, School of Advanced Technologies in Medicine, Tehran University of Medical Sciences, Tehran, Iran.

*Correspondence to: Gholamreza Hassanzadeh, (E-mail: hassanzadeh@tums.ac.ir).

(Submitted: 12 August 2021 - Revised version received: 27 August 2021 - Accepted: 09 September 2021 - Published online: 26 October 2021)

\begin{abstract}
Spinal cord injury $(\mathrm{SCl})$ is a neuro-destruction occurred from a complete or incomplete, traumatic or non-traumatic that results in degeneration, structural, biochemical, and physiological changes of tissue. SCl is a clinical problem associated with impairments in different aspects of the patient's life. The pathophysiology of SCI involves a primary phase that directly disrupts axons, cell membranes, and blood vessels. This primary phase is followed by a secondary phase involving vascular dysfunction, ischemia, excitotoxicity, oxidative stress, inflammation, and cell death. If this second phase isn't managed, it will result in many pathological processes that will cause several clinical complications. The aim of rehabilitation and other treatments is to enhance the functional level and to reduce secondary morbidity as well as improve the quality of health of the patient. SCI results in different complications in different organs of the individual. Early diagnosis, treatment, and prevention of complications in SCl patients are very important for limiting these complications. This review was carried out in order review the data about clinical complications associated with $\mathrm{SCl}$, including multiple organ dysfunction, systemic inflammation, immune suppression, neurogenic shock, autonomic dysreflexia, orthostatic hypotension, temperature regulation, sweat secretion, respiratory complications and dysphagia, thromboembolism, urinary system, reproductive system, skeletal muscle, bone, liver, spleen and gastrointestinal tract. The purpose of this narrative review is to provide knowledge on the $\mathrm{SCl}$ complications, sign and symptoms, risk factors prevention and treatment of complications caused by SCl.

Keywords: Spinal cord injury, Inflammation, Oxidative stress, Clinical complications
\end{abstract}

\section{Introduction}

Spinal cord injury (SCI) is a clinical problem associated with remarkable financial as well as the emotional burden on individual patient, families, and society as well. Approximately, there is incidence of SCI of about 10-80 cases per million populations in the world..$^{1-3}$ Most of the SCI result of tetraplegia (51.57\%), followed by paraplegia with $(45.9 \%)$. SCI due to motor vehicle accident account in almost one-half of the injuries worldwide, followed by SCI due to falls, SCI due to violence (like gunshot), and SCI due to sports activities. ${ }^{4}$ Alcoholism is one of the factors contributing to SCI with $25 \%$ new cases of $\mathrm{SCI}^{3}$ as underlying spine disorder like cervical spondylosis, osteoporosis, atlantoaxial instability, and spinal arthropathies can lead to SCI, too. ${ }^{2,5}$ The extent of SCI depend on the severity of the initial injury, as well the financial burden depends also between individual patients, with the estimated cost of 500,000 to 2 million US dollars on individual patient's lifetime. ${ }^{2}$ Epidemiological studies revealed that the incidence of traumatic SCI in the US is between 27 to 83 per million, in Europe approximately about 10-30 new cases per million. ${ }^{6}$ In developed areas such as Western Europe (16/million), Australia (15/million) and North America (39/million). Falls on level ground are the most common cause of SCI in older countries such as Western Europe (37\%) and Japan (42\%). Violence is one of the common causes of SCI in developing regions such as North Africa/ Middle East (24\%), Sub-Saharan Africa (38\%) and Latin America (22\%). ${ }^{7,8}$ A research conducted in 2008 in Tehran based on population, reported that the prevalence of SCI was 4.4 per 10,000 populations. ${ }^{9}$ Rahimi Movaghar et al. (2013), reported the incidence of SCI in developing countries has a rate of 25.5 per million per year, which ranged from 2.1 to 130.7 per million per year. ${ }^{10}$ Also, men are more prone to SCI in the world than women, although there are differences in the data based on the countries. ${ }^{7}$ Mechanism of SCI categorized into primary and secondary injury, with former resulting from pathologic flexion, compression, rotation, contusion, extension, shearing, fracture-dislocation, ligamentous tears or disruption as well as herniation of intervertebral disk. The primary mechanical injury that happened at the time of injury is followed by a secondary injury phase involving vascular dysfunction, edema, ischemia, excitotoxicity, inflammation, mitochondrial dysfunction, and delayed apoptotic cell death. ${ }^{11-16}$ A report from Gholaminejhad et al. (2017), revealed that the stress oxidative level will increase as one of the complications of SCI, finally may result to neurons disruption in animal model. ${ }^{17}$ There are series of complication occurred as a result of SCI starting from primary injury to secondary injury, most often if care is not taken primary injury leads to the secondary injury that increases damage to previously injured spinal cord, it has shown that overexpression of cytokines that are important mediator for inflammation following SCI. ${ }^{18,19}$ SCI can initiate biochemical and molecular events like inflammation which one of the key factor in neurodegeneration development..$^{20}$ In this paper, the various clinical complications due to SCI were discussed. This narrative review adds to the knowledge of how spinal cord injury occurs, the various complications resulted by spinal cord injury, through the knowledge of different complications immediate attention will be giving to spinal cord injury patients at the early stage. Scopus search, Google Scholar search, PubMed search are the search engines used to get the information for this review. 


\section{Multiple Organ Dysfunctions}

Apart from impairments to sensation and voluntary movement, SCI interrupts the autonomic nervous system and leads to dysfunction or failure in multiple organs due to a vital role of the spinal cord in coordinating bodily functions. ${ }^{21}$ Short term as well as long complications due to SCI may happen in the nervous system (like neurogenic pain and depression), in lungs (pulmonary edema and respiratory failure), in cardiovascular system (like autonomic dysreflexia and orthostatic hypotension), in spleen (like splenic atrophy and leukopenia), in urinary tract (neurogenic bladder, urinary tract infection as well as kidney damage), in skeletal muscle (muscle spasticity and atrophy), in soft tissue as well as bone (osteoporosis and heterotopic ossification), in skin (pressure sores), there are also sexual dysfunction, hepatic pathology, neurogenic bowel dysfunction, syringomyelia as well as high susceptibility to infection. Some SCI complications if care is not taken can easily cause the death of the patient, such as liver, kidney as well as lungs damage (Figure 1). ${ }^{21-24}$ Multiple organ dysfunctions due to SCI are complex regulation by various components. Cranial nerves that originate from brainstem (pons and medulla) regulate the functions of multiple organs, the brainstem reflexes were found to be changed in SCI patients. ${ }^{25}$ This shows a complex relationship between multiple organ dysfunction, SCI and altered brainstem activity. This suggests that a good care should be given to the brainstem's role in multiple organ dysfunctions due to $\mathrm{SCI} .^{25}$

\section{Systemic Inflammation}

The local inflammatory microenvironment around the injured spinal cord is the aggregation of degenerating neurons, damaged myelin sheath, damaged endothelial cells as well as activated glial and infiltrating cells, this microenvironment yields different kind of pro-inflammatory mediators. ${ }^{26,27}$ Apart from this intraspinal inflammation, SCI may results in systemic inflammatory response syndrome (SIRS), this is a life-threatening situation that can affect other organs, such as liver, kidney, and lung. ${ }^{28}$ Previous research revealed that there is a functional relationship between systemic inflammation and pathogenesis of post injury complications: patients with SIRS-positive have more injury severity with more chances of complications compared to SIRS-negative patients. ${ }^{29}$ There are some other different factors like dysregulation of the neuroendocrine system and altered neuroimmune regulation, known as major key factors in determinants of the onset as well as the development of post-SCI systemic inflammation. For example, SCI induces the hypothalamic-pituitary-adrenal axis, results in increased macrophage migration inhibitory factor processing via pituitary gland. ${ }^{30}$ Macrophage migration inhibitory factor is one of the key factors in systemic inflammation, revealing that SCI-elicited neuroendocrine changes lead to the advancement of systemic inflammation. Chronic activation of microglia, the neuroimmune cells of the central nervous system, happens in the hippocampus and cerebral cortex following SCI; this is showing that neuroimmune dysregulation played an important function in systemic inflammation after SCI. ${ }^{31}$ A research conducted by Zandedel et al., (2016) reported that stromal cell-derived factor-1 alpha (SDF-1 $\alpha$ ) or CXCL12 is the main principal cytokine with numerous functions in the brain at fetal development as well as adult period. The inflammatory response occurred due to SCI requires the processing of interleukin-1beta (IL-1 $\beta$ ) as well as IL-18 mediated by caspase-1 in which an intracellular multiprotein complex control it (inflammasome). ${ }^{32}$

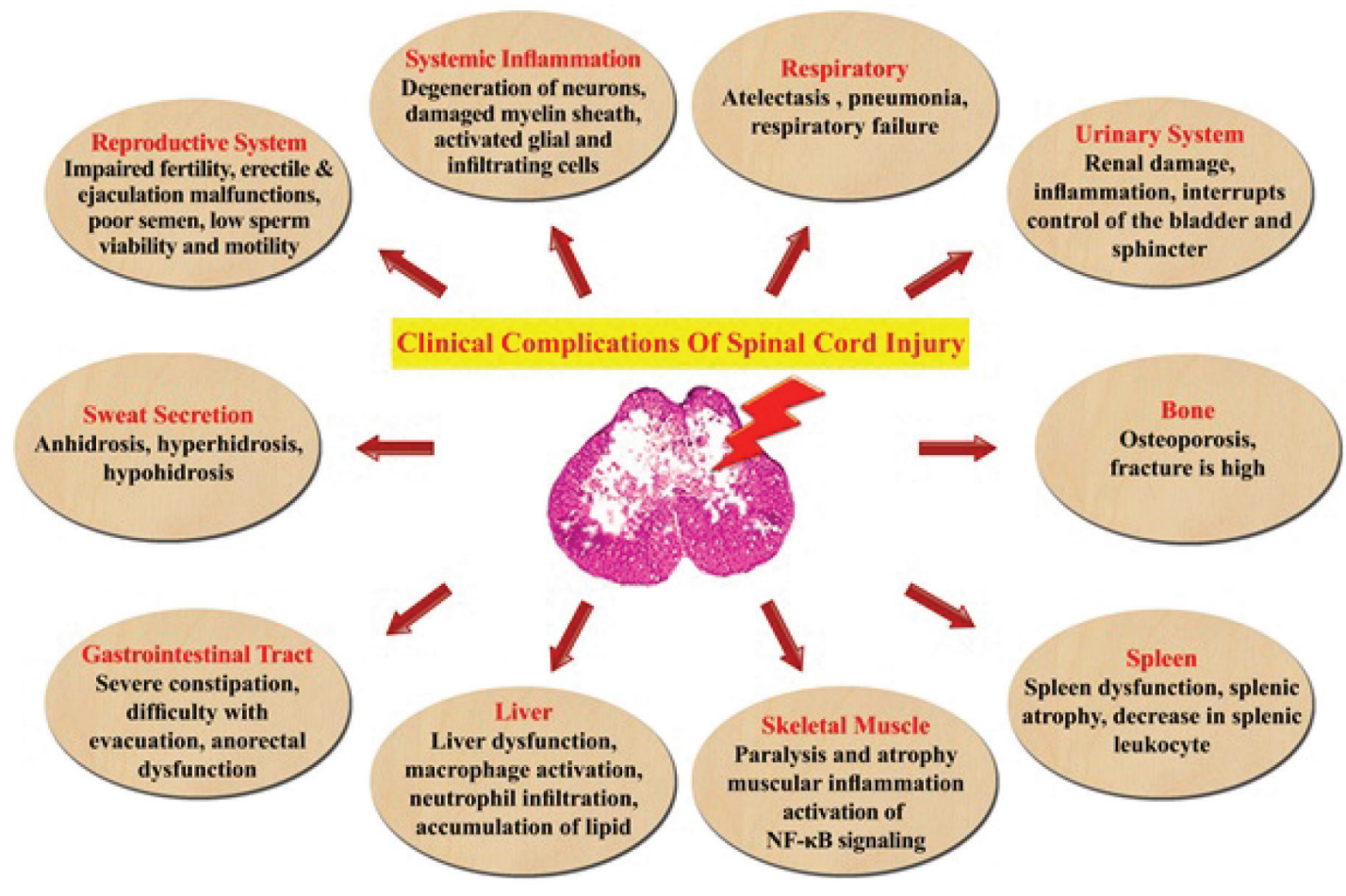

Fig. 1 Clinical complications of spinal cord injury. After spinal cord injury, several clinical complications occur in the short term or the long term. Some of these clinical complications include disorders in the reproductive system, respiratory system, digestive system, urinary system, sweat secretion, skeletal muscles, liver, spleen, bones and systemic inflammation that afflict a person with physical, psychological, social and economic problems. 


\section{Immune Suppression}

Complications occur on the immune system as result of SCI known as SCI-induced immune depression syndrome (SCI-IDS), due to dysregulation of the sympathetic nervous system as well as immune organ dysfunction. ${ }^{33}$ SCI can result in sympathetic nervous system malfunction instantly through prominent projections of the thoracolumbar spinal cord to sympathetic ganglion or directly through damaging supraspinal control by the hypothalamic-pituitary-adrenal axis. SCI-IDS, revealed by the loss of splenocytes as well as leukopenia, is a presumed self-defense mechanism that decreases potential autoimmunity to self-antigens released by damaged in the CNS. ${ }^{34}$ Report from different sources has shown that SCI-IDS worsens neurological environments and damages the functional recovery of SCI patients. Riegger et al., (2009) revealed that a remarkable decrease in the amount of circulating cells associated with innate and adaptive immunity in the acute phase after SCI on rat model..$^{35}$ Similar reports were also made in a pilot research that involves 16 patients with SCI and 10 healthy individuals as control: decreased monocytes, T lymphocytes, and B-lymphocytes, but granulocytes were not seen in the blood circulation within 24 hours following SCI ${ }^{36}$ SCI-IDS has a vital clinical relevance, as SCI patients show a higher susceptibility to different infections (like wound infections and pneumonia) ${ }^{37}$ as well as poor functional recovery. ${ }^{38}$ Autonomic dysreflexia, as well as the expansion of myeloid-derived suppressor cells after SCI, has a mutual relationship with SCI-IDS. ${ }^{39}$

\section{Neurogenic Shock}

At the level of cervical vertebra of SCI in human, the common features of neurogenic shock are severe hypotension as well as continuance bradycardia. ${ }^{40}$ In a study conducted by Glenn and Bergman (1997) revealed that chronic hypotension was seen 31 tetraplegic subjects examined with chronic SCI, most of the subjects need pressure therapy so that the arterial blood pressure will be maintained. ${ }^{41}$ Apart from pronounced hypotension, the majority of the patients with SCI experience chronic abnormalities in heart rate. Bradycardia was seen in $64-77 \%$ of patients with cervical SCI at the acute post-injury level and was so chronic and frequent at the first 5 weeks after the injury. ${ }^{42}$ Furthermore, when the injury is at the level of mid-thoracic spinal cord, leaving cardiac sympathetic neurons under brainstem control, the severity of bradycardia problem is very less. Furlan et al. (2003) revealed that the hypotension and bradycardia seen at the beginning following the injury persisted in the individuals with more chronic injury of the descending cardiovascular autonomic cascades. ${ }^{43}$ Apart from neurogenic shock, SCI as well associated with "spinal shock".44,45 These are two different complications of SCI, neurogenic shock is identified by changes happening in blood pressure control after SCI, while spinal shock is identified by a marked decrease or abolition of motor, sensory or reflex activities of the cord under the level of injury. ${ }^{45}$ Clinically, spinal shock period takes about 1 day to 2 weeks in human, with mean period of 4 and 6 weeks after the injury. Traditionally the ideas of the medical course of the recovery of spinal shock were associated with the appearance of some groups of reflexes. For instance, most clinicians assumed that spinal shock had ended when the emergence of initial reflexes, like the bulbocavernosus reflex, happened at the beginning after SCI, some assumed with the recovery of deep tendon reflexes at two weeks after the injury, while other groups of clinicians categorized the end of spinal shock as the time after 2 months they recovered bladder voiding reflexes. ${ }^{45}$

\section{Autonomic Dysreflexia}

Patients with cervical or high thoracic SCI experience life-long abnormalities of blood pressure control. ${ }^{46,47}$ Most often, the resting arterial blood vessels pressure in these patients is lower when compared with normal individuals, usually associated with disabling event of orthostatic hypotension. Nevertheless, clinical complications of autonomic dysreflexia, associated with high hypertension together with a pounding headache, sometimes accompanied by slow heart rate as well as upper body flushing, in which systolic blood pressure may rise up to $300 \mathrm{mmHg}$. Untreated autonomic dysreflexia may results in serious complication such as retinal detachment, intracranial hemorrhage, seizures and death. ${ }^{48}$ Majority of non-noxious and noxious stimuli like bowel and bladder distension, pressure sores and spasticity may stimulate the sudden high rate in arterial blood pressure of autonomic dysreflexia. ${ }^{47}$ These cardiovascular complications are associated with autonomic instability, due to the changes happening within the spinal autonomic circuits in stages of SCI in acute and chronic stages. ${ }^{46,47}$ The damaging of the descending vasomotor pathways leads to the loss of excitatory supraspinal input to the sympathetic preganglionic neurons and is assumed to be the main factor responsible for the lack of sympathetic tone as well as continuance arterial hypotension observed following SCI. ${ }^{43}$

\section{Orthostatic Hypotension}

Low arterial blood pressure is another complication occurred due to SCI both acute and chronic. a study reported that there was an inverse linear relationship between the degree of resting blood pressure as well as SCI. ${ }^{46,49}$ The lower resting blood pressure is assumed to be secondary to the decrease in sympathetic nervous activity below the degree of the injured spinal cord. Apart from low blood pressure, patients with SCI experience other complication of the drop in blood pressure in the upright posture (orthostatic hypotension), most especially in the acute phase of the injury. ${ }^{49}$ The symptoms of orthostatic hypotension in with SCI patients' are the same as those individuals without SCI experiencing orthostatic hypotension, and all are related to cerebral hypoperfusion. ${ }^{50}$ The common symptoms usually seen are light-headedness, dyspnea, fatigue or weakness, dizziness, blurred vision and restlessness. ${ }^{51} \mathrm{~A}$ study by Illman et al., (2000) reported that $41.1 \%$ of patients with SCI that developed orthostatic hypotension were seen asymptomatic regardless of significant falls in blood pressure, it was also documented that orthostatic hypotension is a common complication among patients with SCI. ${ }^{52}$ Orthostatic hypotension due to SCI seems to be associated with excessive pooling of blood in the viscera as well as dependent extremities, probably caused by low level or absence of efferent sympathetic preganglionic neurons below the injured area. ${ }^{49}$ This is possibly to be compounded by the loss of lower limbs muscle function that identified to be essential in counteracting venous pooling in the upright level. The remaining excessive venous pooling in the lower limbs and decreased blood ratio within 
the intrathoracic veins results in a decreased pressure in the veins that drain through the atria of the heart. ${ }^{53}$ These will leads to reduce in ventricular end-diastolic filling pressure and stroke volume, ${ }^{54}$ resulting in the low in heart output as well as arterial pressure. Tachycardia may happen due to the decrease cardiac parasympathetic (vagal) activity, reflexly produced by unloading the arterial baroreceptors, but this activity most usually is too small to compensate for the reduced stroke volume as well as blood pressure remains low.

\section{Temperature Regulation}

In the ability to control temperature by SCI patients is among the clinical complications caused by SCI, most usually occurred with patients affected by cervical as well as thoracic SCI. This is occurred due to decreases sensory input to thermo-regulating centers as well as loss of sympathetic control of temperature and sweet regulation lower than the affected area. ${ }^{55}$ There are a lot of thermoregulation complications caused by SCI. Some SCI patients were found to have poikilothermia, in the ability to maintain a normal temperature notwithstanding of the ambient temperature. SCI above T8 is usually related to actuating temperature, hyperthermia as well as hypothermia. ${ }^{56}$

\section{Sweat Secretion}

The innervations of sweat glands are mostly by the upper region of the body from T1-T5 spinal cord segments, at the lower part innervated by T6-L2 spinal cord segments. Hypothalamus and amygdala are the regions where supraspinal control of sweat excretion occurred. ${ }^{55}$ As results of SCI changes in sweat secretion will occur, the absence of sweating (anhidrosis), excessive sweating (hyperhidrosis), and diminished sweating (hypohidrosis) may all occur following SCI. ${ }^{55}$ Excessive sweating is a typical complication seen in SCI patients. ${ }^{57}$ In most of the patients, episodic hyperhidrosis is mostly related to other autonomic dysfunctions like autonomic dysreflexia as well as orthostatic hypotension, or with post-traumatic syringomyelia. The typical symptoms seen are minimal or abolished sweating below the injury and profuse sweating above the injured area. This is occurred due to the compensatory high in secretion of sweat above the level of the injured area because of the loss of sympathetic stimulation below the injured area, which leads to decrease in production of sweat. ${ }^{58}$ There is also the possibility of sweat production exclusively below the level of the injured area. This kind of sweating is known as reflex sweating and is mostly a symptom of massive autonomic response that happened specifically with cervical and high thoracic SCI. ${ }^{58}$

\section{Respiratory Complications}

SCI at the cervical region has major complications on the pulmonary system, as well respiratory difficulties are among the most complications and can lead to frequent death, both in the acute and chronic level of SCI. ${ }^{59}$ Results from the previous research revealed that $67 \%$ of acute SCI individuals have severe respiratory problems at the first day of the injury; atelectasis $36.4 \%$, pneumonia $31.4 \%$ as well as respiratory failure $22.6 \% .{ }^{60}$ It was also revealed that in the acute phase $84 \%$ of SCI patients with injuries above $\mathrm{C} 4,6 \%$ with injuries from $\mathrm{C} 5-\mathrm{C} 8$ would develop respiratory complications. ${ }^{61}$ Regular monitoring of respiration on SCI patients with such injuries is advisable. There is possibility of $56 \%$ of SCI patients with injuries at the level of T1-T12 to develop severe respiratory problems. ${ }^{62} 30-50 \%$ reduction of vital capacity is observed in the first week of injury in injured patients at the level of C5-C6. Vital capacity, as well as arterial blood gases, should be measured regularly until the patient is normal. ${ }^{63}$

\section{Thromboembolism}

SCI patients have a higher risk of coagulation complications as well as venous stasis due to physical inactivity, altered hemostasis with decreased fibrinolytic activity and high factor VIII activity. ${ }^{64}$ The patients also are at high risk of thromboembolism. ${ }^{65}$ At the first year of injury, the chances of deep vein thrombosis, as well as pulmonary embolism, are assumed to be $15 \%$ and $5 \%$ respectively. ${ }^{66}$ The chances are higher at $2-3$ weeks of the injury, at 3 months following the injury it will be at a small peak. ${ }^{67}$ At the chronic stage, the incidence of thromboembolism is less than $2 \% .{ }^{64}$

\section{Urinary System}

Patients with SCI have high risk of developing urinary tract complications as well as renal damage, in which both can result in fatal. ${ }^{68}$ Apart from the direct loss of neuronal input following the injury, inflammation has been involved in the pathogenesis of urinary tract malfunction in patients with SCI. The inflammation that is possibly occurred due to SCI is the production of pro-inflammatory cytokines (IL-1 $\beta$, IL-6, and TNF- $\alpha$ ), infiltration of immune cells, upregulation of inducible nitric oxide synthase, myeloperoxidase as well as cyclooxygenase-2, then activation of NF- $\kappa B$ B ${ }^{68,69}$ SCI caused complication in bladder, interrupts control of the bladder. ${ }^{70}$ As a result of SCI immediately after the injury, the bladder as well as sphincter is frequently hypotonic. At the chronic stage the bladder dysfunction is categorized as either upper or lower motor neuron syndrome. ${ }^{70}$ Upper motor neuron syndrome known as reflex bladder result in cortical inhibition of sacral reflex arcs because of disturbance of descending spinal tracts, results in detrusor hyperactivity mostly together with detrusor sphincter dyssynergia. ${ }^{71}$ Suppression of the stretch reflex by the pontine storage center is eliminated. A minor quantity of stretch will provide a contraction of the bladder wall; the external urethral sphincter has no voluntary control, leading in recurrent and spontaneous voiding. ${ }^{71}$ Lower motor neuron syndrome occurred due to injury to the sacral region S2-S4, which is part of the autonomic nervous system leading in diminished motor stimulation of the bladder and decreased or lack of contractility of the detrusor and eventually an enlarged bladder. $^{72}$

\section{Reproductive System}

Impaired fertility is among the major complications occurred in men with SCI that result in erectile as well as ejaculation malfunctions. Semen analysis of SCI patients are always poor, there is much evidence from previous research reported that a low sperm viability, motility, leukocytospermia, and high sperm DNA fragmentation are common among men with SCI. ${ }^{73,74}$ Most of the male SCI patients suffer a lot from infertility. Nucleotide-binding oligomerization domain-like receptors 
NOD-like receptors (NLRs) are the receptors that conjoin with the inflammasome complex. Results from different studies revealed that inflammasomes are one of the key factors for secreting cytokines in semen. Reactive oxygen species (ROS) is one of the agents responsible to initiate inflammasome activation. Genital infections as a result of SCI can bring about ROS generation. ${ }^{75}$ Only a few studies revealed testicular tissue become involved post-SCI. Impaired spermatogenesis, apoptosis, vast germ cell, inflammatory cytokines elevation, and blood-testis barriers disruption, as well as leukocytes influx, has been shown as abnormal changes in the testis of SCI patients, result to the inflammatory event and unstable niche in this tissue. ${ }^{76}$ A study conducted by Nikmehr et al., (2017), examined sperm parameters of SCI using rats' model at acute as well as chronic phases. The result shows a fall in sperm count by half after one day and a third after three days post SCI. The severe decrease in sperm count was very significant in the acute phase, sperm motility was also decreased following SCI on acute as well as chronic phases compared to the control group. ${ }^{73}$ SCI, a neurogenic impairment, resulted to infertility by disturbing the plasma testosterone balance which is very difficult to be restored by exogenous testosterone administration. SCI results in some alteration in oxidative markers, with the reduced free radical scavenging activities of GPx and SOD, ${ }^{77}$ as well as, increased MDA concentration and NLRP3 expression after SCI. ${ }^{75}$

\section{Skeletal Muscle}

SCI makes paralysis and atrophy on the skeletal muscle, especially the muscles controlled by the spinal cord below the level of the injury. ${ }^{78}$ Physiological examinations have shown many alterations in the properties of paralyzed muscles from patients with SCI, such as reduced mass area, high susceptibility to fatigue, decreased muscle cross-sectional area as well as the increased proportion of fast glycolytic muscular fibers. ${ }^{79}$ Muscular inflammation can be seen in the acute phase of SCI prior to muscular atrophy. ${ }^{80}$ In long period SCI, muscle atrophy is related with the remarkable elevation of inflammatory mediators (such as IL-1 $\beta$, IL- 6 , and TNF- $\alpha$ ) as well as activation of $\mathrm{NF}-\kappa \mathrm{B}$ signaling, ${ }^{81}$ which is the main agent that regulates the inflammatory state in muscle atrophy. ${ }^{82}$

\section{Bone}

Osteoporosis, which is defined as the loss of bone mineral density (BMD), is formed as a result of SCI. ${ }^{83}$ The distal femur, proximal tibia as well as distal boney sites at sub-lesional area are the major susceptible to BMD loss. ${ }^{84}$ The low level of BMD is increasing following SCI; as well the possibility of patients' fracture is high, ${ }^{85}$ there are other various factors that contribute the pathogenesis of osteoporosis as a result of SCI. Apart from the deficiency in neuronal control, hormonal regulation as well as vascular function, ${ }^{86}$ the inflammatory microenvironment in bone brings about osteoclast differentiation as well as bone loss. ${ }^{87}$

\section{Liver}

From the previous report, it was revealed that there are hepatic complications due to SCI. ${ }^{88}$ There are many reports that show liver dysfunction can be related to SCI, as the liver plays a significant role in the metabolic dysfunction usually seen in patients with SCI. Experimental research using animal model revealed that SCI activates macrophage activation, neutrophil infiltration, expression of pro-inflammatory cytokines as well as chemokines in the liver. ${ }^{89}$ This inflammation occurs immediately following the injury, ${ }^{90}$ and its severity is related to the level of injury. ${ }^{91}$ A significant amount of accumulated lipid has been seen in rodent liver after SCI. ${ }^{92}$ Given the proinflammatory as well as cytotoxic effects of myelin-laden macrophage related to the accumulation of lipid in the SCI, ${ }^{93}$ macrophage-mediated inflammation considerably leads to hepatic dysfunction following SCI.

\section{Spleen}

Spleen is a very vital lymphoid organ functioned for infiltration of monocytes in the injured spinal cord; spleen is innervated by the autonomic nervous system and regulated by the high thoracic spinal cord. A research using rat model has shown a significant spleen dysfunction due to SCI at the T3 level. Spleen dysfunction as a result of SCI at T3 level was revealed by splenic atrophy with decrease in size, decrease in the amount of splenic leukocyte and increased splenic norepinephrine was seen. ${ }^{94,95}$ SCI mice induced with viral infection revealed impaired immune responses as well as decreased survival, and these results seen in mice were related with deficient CD4+ and CD8+ T cell functions, deficient primary antibody response as well as suppressed activation of macrophages. ${ }^{96}$ This indicates that dysfunction of the spleen may possibly result in immune suppression in patients with SCI. Remarkably; post-SCI mRNA levels of pro-inflammatory cytokines IL-17, as well as IL-23, were seen upregulated in tissue spleen of rat model by STAT3 signaling, ${ }^{97}$ consequently, crosstalk between spleen and SCI could be mediated by neuroinflammation.

\section{Gastrointestinal Tract}

There are many complications occurred due to SCI in the gastrointestinal tract (GIT), for example, severe constipation, difficulty with evacuation, painful defecation or incontinence, is advisable to restrict and limit the diet and outdoor activities of SCI patients. ${ }^{98}$ Despite the fact that function of GIT is basically regulated by its own intrinsic nervous system as well as autonomic control by the brainstem, SCI may cause the destruction of neuronal control of GIT sensory as well as motor functions, leading to neurogenic bowel dysfunction (NBD). It was estimated that $50 \%$ of SCI patients are having moderate to severe $\mathrm{NBD},{ }^{99}$ it appears that abnormal bowel function has a more negative influence on the quality of life of patients with SCI. ${ }^{100,101}$ The clinical presentations of NBD with SCI are prolonged bowel transit time; decrease colonic motility as well as anorectal dysfunction. ${ }^{102}$ Even though there is inflammation in colonic lesions of patients with $\mathrm{SCI},{ }^{103}$ the association between systemic inflammation as well as NBD is not well understood. A report from Guo et al., (2016) on rat model of NBD after SCI shows that upregulation of neuronal nitric oxide synthase leads to colonic dysfunction, ${ }^{104}$ thus creating inflammation as a possible target for reducing post-SCI NBD.

\section{Conclusion}

SCI leads to different complications in various parts of the body, most often, primary injury gives rise to secondary injury 
that increases damage to the previously injured spinal cord. Among several processes of secondary injury phase, it seems inflammation is most important because it involves in many pathological problems. Therefore, suppression of inflammation maybe is a good target for degenerative diseases. Also, knowledge of possible complications by SCI is very vital because the complications may be life-threatening and may lead to prolonging rehabilitation for SCI patients, also early detection and treatment of the complications will help in managing the patient. Even though there is no way to reverse damage to the spinal cord. But there are various researches continually working on new treatments, including transplanting stem cells and medications that may promote nerve cell regeneration or improve the function of nerves that remain after SCI.

\section{Conflicts of Interest}

None.

\section{References}

1. Grant RA, Quon JL, Abbed KM (2015) Management of acute traumatic spinal cord injury. Current treatment options in neurology 17 (2):6.

2. Sekhon LH, Fehlings MG (2001) Epidemiology, demographics, and pathophysiology of acute spinal cord injury. Spine 26 (24S):S2-S12.

3. Thompson C, Mutch J, Parent S, Mac-Thiong J-M (2015) The changing demographics of traumatic spinal cord injury: An 11-year study of 83 patients. The journal of spinal cord medicine 38 (2):214-223.

4. Jackson AB, Dijkers M, DeVivo MJ, Poczatek RB (2004) A demographic profile of new traumatic spinal cord injuries: change and stability over 30 years. Archives of physical medicine and rehabilitation 85 (11):1740-1748

5. Myers ER, Wilson SE (1997) Biomechanics of osteoporosis and vertebral fracture. Spine 22 (24):25S-31S.

6. Hyun JK, Kim H-W (2010) Clinical and experimental advances in regeneration of spinal cord injury. Journal of tissue engineering 1 (1):650857.

7. Chiu W-T, Lin H-C, Lam C, Chu S-F, Chiang Y-H, Tsai S-H (2010) Epidemiology of traumatic spinal cord injury: comparisons between developed and developing countries. Asia Pacific Journal of Public Health 22 (1):9-18.

8. Burns AS, O'Connell C (2012) The challenge of spinal cord injury care in the developing world. The journal of spinal cord medicine 35 (1):3-8.

9. Rahimi-Movaghar V, Saadat S, Rasouli MR, Ganji S, Ghahramani M, Zarei $M-R$, Vaccaro AR (2009) Prevalence of spinal cord injury in Tehran, Iran. The journal of spinal cord medicine 32 (4):428-431.

10. Rahimi-Movaghar V, Sayyah MK, Akbari H, Khorramirouz R, Rasouli MR, Moradi-Lakeh M, Shokraneh F, Vaccaro AR (2013) Epidemiology of traumatic spinal cord injury in developing countries: a systematic review. Neuroepidemiology 41 (2):65-85.

11. Tator CH, Fehlings MG (1991) Review of the secondary injury theory of acute spinal cord trauma with emphasis on vascular mechanisms. Journal of neurosurgery 75 (1):15-26.

12. Ghaffari N, Hassanzadeh G, Nowrouzi A, Gholaminejhad M, Mokhtari T, Seifali R, Mohammed I, Akbari M (2018) Antioxidative and antiinflammatory effects of Cichorium intybus L. seed extract in ischemia/ reperfusion injury model of rat spinal cord. Journal of Contemporary Medical Sciences 4 (4).

13. Mohammed I, ljaz S, Mokhtari T, Gholaminejhad M, Mahdavipour M, Jameie B, Akbari M, Hassanzadeh G. Subventricular zone-derived extracellular vesicles promote functional recovery in rat model of spinal cord injury by inhibition of NLRP3 inflammasome complex formation. Metabolic brain disease. 2020 Jun 1;35(5).

14. Rowland JW, Hawryluk GW, Kwon B, Fehlings MG (2008) Current status of acute spinal cord injury pathophysiology and emerging therapies: promise on the horizon. Neurosurgical focus 25 (5):E2.

15. Hassanzadeh S, Jameie SB, Soleimani M, Farhadi M, Kerdari M, Danaei N (2018) Coenzyme Q10 Influences on the Levels of TNF- $\alpha$ and IL-10 and the Ratio of $\mathrm{Bax} / \mathrm{Bcl} 2$ in a Menopausal Rat Model Following Lumbar Spinal Cord Injury. Journal of Molecular Neuroscience 65 (2):255-264

16. Hassanzadeh S, Jameie SB, Mehdizadeh M, Soleimani M, Namjoo Z, Soleimani M (2018) FNDC5 expression in Purkinje neurons of adult male rats with acute spinal cord injury following treatment with methylprednisolone. Neuropeptides 70:16-25.

17. Gholaminejhad M, Arabzadeh S, Akbari M, Mohamadi Y, Hassanzadeh G (2017) Anti-oxidative and neuroprotective effects of flaxseed on experimental unilateral spinal cord injury in rat. Journal of Contemporary Medical Sciences 3 (10):213-217.

18. Pishva AA, Akbari M, Farahabadi A, Arabkheradmand A, Beyer C, Dashti N, Moradi F, Hassanzadeh G (2016) Effect of estrogen therapy on TNF-a and iNOS gene expression in spinal cord injury model. Acta Medica Iranica 54 (5):296-301.

19. Mohamadi Y, Moghahi SMHN, Mousavi M, Borhani-Haghighi M, Abolhassan F, Kashani IR, Hassanzadeh G (2019) Intrathecal transplantation of Wharton's jelly mesenchymal stem cells suppresses the NLRP1 inflammasome in the rat model of spinal cord injury. Journal of chemical neuroanatomy 97:1-8.

20. Ijaz S, Mohammed I, Gholaminejhad M, Mokhtari T, Akbari M, Hassanzadeh G. Modulating Pro-inflammatory Cytokines, Tissue Damage Magnitude, and Motor Deficit in Spinal Cord Injury with Subventricular Zone-Derived Extracellular Vesicles. Journal of Molecular Neuroscience. 2020;70(3):458-66. doi: 10.1007/s12031-019-01437-2.

21. Stein DM, Menaker J, McQuillan K, Handley C, Aarabi B, Scalea TM (2010) Risk factors for organ dysfunction and failure in patients with acute traumatic cervical spinal cord injury. Neurocritical care 13 (1):29-39.

22. Zimmer MB, Nantwi K, Goshgarian HG (2007) Effect of spinal cord injury on the respiratory system: basic research and current clinical treatment options. Taylor \& Francis,

23. Bilello JF, Davis JW, Cunningham MA, Groom TF, Lemaster D, Sue LP (2003) Cervical spinal cord injury and the need for cardiovascular intervention. Archives of Surgery 138 (10):1127-1129.

24. MacDiarmid S, Mclntyre W, Anthony A, Bailey R, Turner J, Arnold E (2000) Monitoring of renal function in patients with spinal cord injury. BJU international 85 (9):1014-1018.

25. Kumru H, Kofler M (2012) Effect of spinal cord injury and of intrathecal baclofen on brainstem reflexes. Clinical Neurophysiology 123 (1):45-53.

26. Altinors N (2009) Analysis of serum pro-inflammatory cytokine levels after rat spinal cord ischemia/reperfusion injury and correlation with tissue damage. Turkish neurosurgery 19 (4):353-359.

27. Mohamadi Y, Mousavi M, Moogahi SMHN, Abolhassani F, ljaz S, Hassanzadeh G (2018) Effect of Wharton's Jelly Derived Mesenchymal Stem Cells on the Expression of NLRP3 Receptor and Neuroinflammation in Experimental Spinal Cord Injury. Journal of Clinical \& Diagnostic Research $12(10)$.

28. Anthony DC, Couch Y (2014) The systemic response to CNS injury. Experimental neurology 258:105-111.

29. Kesani AK, Urquhart JC, Bedard N, Leelapattana P, Siddiqi F, Gurr KR, Bailey CS (2014) Systemic inflammatory response syndrome in patients with spinal cord injury: does its presence at admission affect patient outcomes? Clinical article. Journal of Neurosurgery: Spine 21 (2):296-302

30. Lerch JK, Puga DA, Bloom O, Popovich PG. Glucocorticoids and macrophage migration inhibitory factor (MIF) are neuroendocrine modulators of inflammation and neuropathic pain after spinal cord injury. In: Seminars in immunology, 2014. vol 5. Elsevier, pp. 409-414.

31. Wu J, Zhao Z, Sabirzhanov B, Stoica BA, Kumar A, Luo T, Skovira J, Faden Al (2014) Spinal cord injury causes brain inflammation associated with cognitive and affective changes: role of cell cycle pathways. Journal of Neuroscience 34 (33):10989-11006.

32. Zendedel A, Johann S, Mehrabi S, Joghataei M-t, Hassanzadeh G, Kipp M, Beyer C (2016) Activation and regulation of NLRP3 inflammasome by intrathecal application of SDF-1a in a spinal cord injury model. Molecular neurobiology 53 (5):3063-3075.

33. Kopp MA, Druschel C, Meisel C, Liebscher T, Prilipp E, Watzlawick R, Cinelli P, Niedeggen A, Schaser K-D, Wanner GA (2013) The SClentinel studyprospective multicenter study to define the spinal cord injury-induced immune depression syndrome (SCI-IDS)-study protocol and interim feasibility data. BMC neurology 13 (1):168.

34. Schwab JM, Zhang Y, Kopp MA, Brommer B, Popovich PG (2014) The paradox of chronic neuroinflammation, systemic immune suppression, autoimmunity after traumatic chronic spinal cord injury. Experimental neurology 258:121-129.

35. Riegger T, Conrad S, Liu K, Schluesener HJ, Adibzahdeh M, Schwab JM (2007) Spinal cord injury-induced immune depression syndrome (SCI-IDS) European Journal of Neuroscience 25 (6):1743-1747. 
36. Riegger T, Conrad S, Schluesener H, Kaps H-P, Badke A, Baron C, Gerstein J, Dietz K, Abdizahdeh M, Schwab J (2009) Immune depression syndrome following human spinal cord injury (SCI): a pilot study. Neuroscience 158 (3):1194-1199.

37. Brommer B, Engel O, Kopp MA, Watzlawick R, Müller S, Prüss H, Chen Y, DeVivo MJ, Finkenstaedt FW, Dirnagl U (2016) Spinal cord injury-induced immune deficiency syndrome enhances infection susceptibility dependent on lesion level. Brain 139 (3):692-707.

38. Failli V, Kopp MA, Gericke C, Martus P, Klingbeil S, Brommer B, Laginha I, Chen Y, DeVivo MJ, Dirnagl U (2012) Functional neurological recovery after spinal cord injury is impaired in patients with infections. Brain 135 (11):3238-3250.

39. Wang L, Yu W-b, Tao L-y, Xu Q (2016) Myeloid-derived suppressor cells mediate immune suppression in spinal cord injury. Journal of neuroimmunology 290:96-102.

40. Atkinson PP, Atkinson JL Spinal shock. In: Mayo Clinic Proceedings, 1996 vol 4. Elsevier, pp 384-389.

41. Glenn M, Bergman SB (1997) Cardiovascular changes following spinal cord injury. Topics in Spinal Cord Injury Rehabilitation 2 (4):47-53.

42. Lehmann KG, Lane JG, Piepmeier JM, Batsford WP (1987) Cardiovascula abnormalities accompanying acute spinal cord injury in humans: incidence, time course and severity. Journal of the American College of Cardiology 10 (1):46-52

43. Furlan JC, Fehlings MG, Shannon P, Norenberg MD, Krassioukov AV (2003) Descending vasomotor pathways in humans: correlation between axonal preservation and cardiovascular dysfunction after spinal cord injury. Journal of neurotrauma 20 (12):1351-1363.

44. Nacimiento W, Noth J (1999) What, if anything, is spinal shock? Archives of neurology 56 (8):1033-1035.

45. Ditunno J, Little J, Tessler A, Burns A (2004) Spinal shock revisited: a fourphase model. Spinal Cord 42 (7):383-395.

46. Mathias C (1992) Investigation of autonomic disorders. Autonomic Faliure, A textbook of clinical disorders of the autonomic nervous system:255-290.

47. Teasell RW, Arnold JMO, Krassioukov A, Delaney GA (2000) Cardiovascular consequences of loss of supraspinal control of the sympathetic nervous system after spinal cord injury. Archives of physical medicine and rehabilitation 81 (4):506-516.

48. Eltorai I, Kim R, Vulpe M, Kasravi H, Ho W (1992) Fatal cerebral hemorrhage due to autonomic dysreflexia in a tetraplegic patient: case report and review. Spinal Cord 30 (5):355.

49. Mathias CJ (1995) Orthostatic hypotension: causes, mechanisms, and influencing factors. Neurology 45 (4 Suppl 5):S6-S11.

50. Cleophas TJ, Kauw FH, Bijl C, Meijers J, Stapper G (1986) Effects of beta adrenergic receptor agonists and antagonists in diabetics with symptoms of postural hypotension: a double-blind, placebo-controlled study. Angiology 37 (11):855-862

51. Sclater A, Alagiakrishnan K (2004) Orthostatic hypotension. A primary care primer for assessment and treatment. Geriatrics (Basel, Switzerland) 59 (8):22-27.

52. Illman A, Stiller K, Williams M (2000) The prevalence of orthostatic hypotension during physiotherapy treatment in patients with an acute spinal cord injury. Spinal Cord 38 (12):741.

53. Faghri PD, Yount JP, Pesce WJ, Seetharama S, Votto JJ (2001) Circulatory hypokinesis and functional electric stimulation during standing in person with spinal cord injury. Archives of physical medicine and rehabilitation 82 (11):1587-1595.

54. Ten Harkel A, Van Lieshout J, Wieling W (1994) Effects of leg muscle pumping and tensing on orthostatic arterial pressure: a study in normal subjects and patients with autonomic failure. Clinical Science 87 (5):553-558.

55. Alexander M, Biering-Sorensen F, Bodner D, Brackett N, Cardenas D, Charlifue S, Creasey G, Dietz V, Ditunno J, Donovan W (2009) International standards to document remaining autonomic function after spinal cord injury. Spinal Cord 47 (1):36-43.

56. Phillips WT, Kiratli BJ, Sarkarati M, Weraarchakul G, Myers J, Franklin BA, Parkash I, Froelicher V (1998) Effect of spinal cord injury on the heart and cardiovascular fitness. Current problems in cardiology 23 (11):641-716.

57. Karlsson A-K (2006) Overview: Autonomic dysfunction in spinal cord injury: clinical presentation of symptoms and signs. Progress in brain research 152:1-8.

58. Yaggie JA, Niemi TJ, Buono MJ (2002) Adaptive sweat gland response after spinal cord injury. Archives of physical medicine and rehabilitation 83 (6):802-805

59. Berney S, Bragge P, Granger C, Opdam H, Denehy L (2011) The acute respiratory management of cervical spinal cord injury in the first 6 weeks after injury: a systematic review. Spinal cord 49 (1):17-29.
60. Kirshblum SC, Groah SL, McKinley WO, Gittler MS, Stiens SA (2002) 1 Etiology, classification, and acute medical management. Archives of physical medicine and rehabilitation 83:S50-S57.

61. Jackson AB, Groomes TE (1994) Incidence of respiratory complications following spinal cord injury. Archives of physical medicine and rehabilitation 75 (3):270-275.

62. Berlly M, Shem K (2007) Respiratory management during the first five days after spinal cord injury. Taylor \& Francis,

63. Tollefsen E, Fondenes O (2012) Respiratory complications associated with spinal cord injury. Tidsskrift for den Norske laegeforening: tidsskrift for praktisk medicin, ny raekke 132 (9):1111-1114.

64. publico/thromboembolism\%20in\%20SCl.pdf Uha-gdo (1999) Prevention of Thromboembolism in Spinal Cord Injury. Consortium for Spinal Cord Medicine:1-29.

65. Ploumis A, Ponnappan R, Maltenfort M, Patel R, Bessey J, Albert T, Harrop J, Fisher C, Bono C, Vaccaro A (2009) Thromboprophylaxis in patients with acute spinal injuries: an evidence-based analysis. JBJS 91 (11):2568-2576.

66. Merli G, Crabbe S, Paluzzi R, Fritz D (1993) Etiology, incidence, and prevention of deep vein thrombosis in acute spinal cord injury. Archives of physical medicine and rehabilitation 74 (11):1199-1205.

67. Lamb GC, Tomski MA, Kaufman J, Maiman DJ (1993) Is chronic spinal cord injury associated with increased risk of venous thromboembolism? The Journal of The American Paraplegia Society 16 (3):153-156.

68. Wang W-G, Xiu R-J, Xu Z-W, Yin Y-X, Feng Y, Cao X-C, Wang P-S (2015) Protective effects of Vitamin C against spinal cord injury-induced renal damage through suppression of NF-KB and proinflammatory cytokines. Neurological Sciences 36 (4):521-526

69. Shunmugavel A, Khan M, Hughes FM, Purves JT, Singh A, Singh I (2015) S-Nitrosoglutathione protects the spinal bladder: Novel therapeutic approach to post-spinal cord injury bladder remodeling. Neurourology and urodynamics 34 (6):519-526.

70. Middleton JW, Mann L, Leong G (2008) Management of spinal cord injury in general practice-part 1. Australian family physician 37 (4):229.

71. Burns AS, Rivas DA, Ditunno JF (2001) The management of neurogenic bladder and sexual dysfunction after spinal cord injury. Spine 26 (24S):S129-S136.

72. Burns AS, Ditunno JF (2001) Establishing prognosis and maximizing functional outcomes after spinal cord injury: a review of current and future directions in rehabilitation management. Spine 26 (24S):S137-S145.

73. Nikmehr B, Bazrafkan M, Hassanzadeh G, Shahverdi A, Gilani MAS, Kiani S, Mokhtari T, Abolhassani F (2017) The correlation of gene expression of inflammasome indicators and impaired fertility in rat model of spinal cord injury: A time course study. Urology journal 14 (6):5057-5063.

74. Choobineh H, Kazemi M, Gilani MAS, Heydari T, Shokri S, Bazrafkan M, Hassanzadeh G (2018) Testosterone Reduces Spinal Cord Injury-Induced Effects on Male Reproduction by Preventing CADM1 Defect. Cell Journal (Yakhteh) 20 (2):138

75. Bazrafkan M, Nikmehr B, Shahverdi A, Hosseini SR, Hassani F, Poorhassan M, Mokhtari T, Abolhassani F, Choobineh H, Beyer C (2018) Lipid peroxidation and its role in the expression of NLRP1a and NLRP3 genes in testicular tissue of male rats: A model of spinal cord injury. Iranian biomedical journal 22 (3):151.

76. Sánchez-Ramos A, Vargas-Baquero E, Martin-de Francisco F, Godino-Durán J, Rodriguez-Carrión I, Ortega-Ortega M, Mordillo-Mateos L, Coperchini F, Rotondi M, Oliviero A (2017) Early spermatogenesis changes in traumatic complete spinal cord-injured adult patients. Spinal cord 55 (6):sc2016184.

77. Choobineh H, Gilani MAS, Pasalar P, Jahanzad I, Ghorbani R, Hassanzadeh G (2016) The effects of testosterone on oxidative stress markers in mice with spinal cord injuries. International journal of fertility \& sterility 10 (1):87.

78. Qin W, Bauman WA, Cardozo C (2010) Bone and muscle loss after spinal cord injury: organ interactions. Annals of the New York Academy of Sciences $1211(1): 66-84$

79. Wu Y, Zhao J, Zhao W, Pan J, Bauman WA, Cardozo CP (2012) Nandrolone normalizes determinants of muscle mass and fiber type after spinal cord injury. Journal of neurotrauma 29 (8):1663-1675.

80. Thakore NP, Samantaray S, Park S, Nozaki K, Smith JA, Cox A, Krause J, Banik NL (2016) Molecular changes in sub-lesional muscle following acute phase of spinal cord injury. Neurochemical research 41 (1-2):44-52.

81. Yarar-Fisher C, Bickel CS, Kelly NA, Stec MJ, Windham ST, McLain AB, Oster RA, Bamman MM (2016) Heightened TWEAK-NF-KB signaling and inflammation-associated fibrosis in paralyzed muscles of men with chronic spinal cord injury. American Journal of Physiology-Endocrinology and Metabolism 310 (9):E754-E761 
82. Jackman RW, Cornwell EW, Wu CL, Kandarian SC (2013) Nuclear factor-kB signalling and transcriptional regulation in skeletal muscle atrophy. Experimental physiology 98 (1):19-24.

83. Qin W, Sun L, Cao J, Peng Y, Collier L, Wu Y, Creasey G, Li J, Qin Y, Jarvis J (2013) The central nervous system (CNS)-independent anti-bone-resorptive activity of muscle contraction and the underlying molecular and cellular signatures. Journal of Biological Chemistry 288 (19):13511-13521.

84. Coupaud S, McLean AN, Purcell M, Fraser MH, Allan DB (2015) Decreases in bone mineral density at cortical and trabecular sites in the tibia and femur during the first year of spinal cord injury. Bone 74:69-75.

85. Bauman WA, Cardozo CP (2015) Osteoporosis in individuals with spinal cord injury. PM\&R 7 (2):188-201.

86. Tan CO, Battaglino RA, Morse LR (2013) Spinal cord injury and osteoporosis: causes, mechanisms, and rehabilitation strategies. International journal of physical medicine \& rehabilitation 1.

87. Baum R, Gravallese EM (2014) Impact of inflammation on the osteoblast in rheumatic diseases. Current osteoporosis reports 12 (1):9-16.

88. Sipski ML, Estores IM, Alexander CJ, Guo X, Chandralapaty S (2004) Lack of justification for routine abdominal ultrasonography in patients with chronic spinal cord injury. Journal of rehabilitation research and development 41 (1):101.

89. Campbell SJ, Zahid I, Losey P, Law S, Jiang Y, Bilgen M, van Rooijen N, Morsali D, Davis AE, Anthony DC (2008) Liver Kupffer cells control the magnitude of the inflammatory response in the injured brain and spinal cord. Neuropharmacology 55 (5):780-787.

90. Hundt H, Fleming J, Phillips J, Lawendy A, Gurr K, Bailey S, Sanders D, Bihari R, Gray D, Parry N (2011) Assessment of hepatic inflammation after spinal cord injury using intravital microscopy. Injury 42 (7):691-696.

91. Fleming JC, Bailey CS, Hundt H, Gurr KR, Bailey SI, Cepinskas G, Lawendy A-R, Badhwar A (2012) Remote inflammatory response in liver is dependent on the segmental level of spinal cord injury. Journal of Trauma and Acute Care Surgery 72 (5):1194-1201.

92. Sauerbeck AD, Laws JL, Bandaru WV, Popovich PG, Haughey NJ, McTigue DM (2015) Spinal cord injury causes chronic liver pathology in rats. Journal of neurotrauma 32 (3):159-169.

93. Guo L, Rolfe AJ, Wang X, Tai W, Cheng Z, Cao K, Chen X, Xu Y, Sun D, Li J (2016) Rescuing macrophage normal function in spinal cord injury with embryonic stem cell conditioned media. Molecular brain 9 (1):48.
94. Lucin KM, Sanders VM, Jones TB, Malarkey WB, Popovich PG (2007) Impaired antibody synthesis after spinal cord injury is level dependent and is due to sympathetic nervous system dysregulation. Experimental neurology 207 (1):75-84.

95.Zhang Y, Guan Z, Reader B, Shawler T, Mandrekar-Colucci S, Huang K, Weil Z, Bratasz A, Wells J, Powell ND (2013) Autonomic dysreflexia causes chronic immune suppression after spinal cord injury. Journal of Neuroscience 33 (32):12970-12981.

96. Zha J, Smith A, Andreansky S, Bracchi-Ricard V, Bethea JR (2014) Chronic thoracic spinal cord injury impairs CD8+ T-cell function by up-regulating programmed cell death-1 expression. Journal of neuroinflammation $11(1): 65$.

97. Zong S, Zeng G, Fang Y, Peng J, Tao Y, Li K, Zhao J (2014) The role of IL-17 promotes spinal cord neuroinflammation via activation of the transcription factor STAT3 after spinal cord injury in the rat. Mediators of inflammation 2014.

98. Han TR, Kim JH, Kwon BS (1998) Chronic gastrointestinal problems and bowel dysfunction in patients with spinal cord injury. Spinal cord 36 (7): 485-490.

99. Liu C-W, Huang C-C, Yang Y-H, Chen S-C, Weng M-C, Huang M-H (2009) Relationship between neurogenic bowel dysfunction and health-related quality of life in persons with spinal cord injury. Journal of rehabilitation medicine 41 (1):35-40.

100. Correa G, Rotter K (2000) Clinical evaluation and management of neurogenic bowel after spinal cord injury. Spinal cord 38 (5):301.

101. Stiens SA, Bergman SB, Goetz LL (1997) Neurogenic bowel dysfunction after spinal cord injury: clinical evaluation and rehabilitative management. Archives of physical medicine and rehabilitation 78 (3):S86-S102.

102. Fajardo NR, Pasiliao R-v, Modeste-Duncan R, Creasey G, Bauman WA Korsten MA (2003) Decreased colonic motility in persons with chronic spinal cord injury. The American journal of gastroenterology 98 (1): $128-134$.

103. Han SJ, Kim CM, Lee JE, Lee TH (2009) Colonoscopic lesions in patients with spinal cord injury. The journal of spinal cord medicine 32 (4):404-407

104. Guo J, Zhu Y, Yang Y, Wang X, Chen B, Zhang W, Xie B, Zhu Z, Yue Y, Cheng J (2016) Electroacupuncture at Zusanli (ST36) ameliorates colonic neuronal nitric oxide synthase upregulation in rats with neurogenic bowel dysfunction following spinal cord injury. Spinal cord 